\begin{tabular}{|c|c|}
\hline Title & $\begin{array}{l}\text { Removals of pesticides and pesticide transformation products during drinking water treatment processes and their } \\
\text { impact on mutagen formation potential after chlorination }\end{array}$ \\
\hline Author(s) & $\begin{array}{l}\text { Matsushita, Taku; Morimoto, A yako; Kuriyama, Taisuke; Matsumoto, Eisuke; Matsui, Y oshihiko; Shirasaki, Nobutaka; } \\
\text { Kondo, T akashi; Takanashi, Hirokazu; Kameya, Takashi }\end{array}$ \\
\hline Citation & $\begin{array}{l}\text { Water research, 138, 67-76 } \\
\text { https://doi.org/10.1016/.watres.2018.01.028 }\end{array}$ \\
\hline Issue Date & 2018-07-01 \\
\hline Doc URL & http:/hdl .handle.net/2115/78769 \\
\hline Rights & $\begin{array}{l}\text { () 2018. This manuscript version is made available under the CC-BY-NC-ND } 4.0 \text { license } \\
\text { http://creativecommons.org/icenses/by-nc-nd/4.0/ }\end{array}$ \\
\hline Rights(URL) & http://creativecommons.org/icenses/by-nc-nd/4.0/ \\
\hline Type & article (author version) \\
\hline File Information & WR_TP_for-HUSCAP.PDF \\
\hline
\end{tabular}

Instructions for use 


\title{
Removals of pesticides and pesticide transformation products during drinking water treatment processes and their impact on mutagen formation potential after chlorination
}

\author{
Taku Matsushita ${ }^{\mathrm{a}, *}$, Ayako Morimoto $^{\mathrm{b}}$, Taisuke Kuriyama $^{\mathrm{b}}$, Eisuke Matsumoto $^{\mathrm{b}}$, Yoshihiko Matsui ${ }^{\mathrm{a}}$, \\ Nobutaka Shirasaki ${ }^{\mathrm{a}}$,Takashi Kondo ${ }^{\mathrm{b}}$,Hirokazu Takanashi ${ }^{\mathrm{c}}$, Takashi Kameya $^{\mathrm{d}}$
}

${ }^{a}$ Faculty of Engineering Hokkaido University, N13W8, Sapporo 060-8628, Japan

${ }^{\mathrm{b}}$ Graduate School of Engineering, Hokkaido University, N13W8, Sapporo 060-8628, Japan

${ }^{\mathrm{c}}$ Faculty of Science and Engineering, Kagoshima University, 1-21-40 Korimoto, Kagoshima 890-0065, Japan

${ }^{\mathrm{d}}$ Faculty of Environment and Information Sciences, Yokohama National University, 79-7 Tokiwadai, Hodogaya, Yokohama 240-8501, Japan

* Corresponding author: E-mail: taku-m@eng.hokudai.ac.jp; Tel./fax: +81-11-706-7279

\begin{abstract}
Removal efficiencies of 28 pesticide transformation products (TPs) and 15 parent pesticides during steps in drinking water treatment (coagulation-sedimentation, activated carbon adsorption, and ozonation) were estimated via laboratory-scale batch experiments, and the mechanisms underlying the removal at each step were elucidated via regression analyses. The removal via powdered activated carbon (PAC) treatment was correlated positively with the $\log K_{\text {ow }}$ at $\mathrm{pH} 7$. The adjusted coefficient of determination $\left(r^{2}\right)$ increased when the energy level of the highest occupied molecular orbital (HOMO) was added as an explanatory variable, the suggestion being that adsorption onto PAC particles was largely governed by hydrophobic interactions. The residual error could be partly explained by $\pi-\pi$ electron donor-acceptor interactions between the graphene surface of the PAC particles and the adsorbates. The removal via ozonation correlated positively with the energy level of the HOMO, probably because compounds with relatively high energy level HOMOs could more easily transfer an electron to the lowest unoccupied molecular orbital of ozone. Overall, the TPs tended to be more difficult to remove via PAC adsorption and ozonation than their parent pesticides. However, the TPs that were difficult to remove via PAC adsorption did not induce strong mutagenicity after chlorination, and the TPs that were associated with strong mutagenicity after chlorination could be removed via PAC adsorption. Therefore, PAC adsorption is hypothesized to be an effective method of treating drinking water to reduce the possibility of post-chlorination mutagenicity associated with both TPs and their parent pesticides.
\end{abstract}

Keywords: Activated carbon adsorption; Coagulation and sedimentation; Disinfection by-product; Ozonation; Removal mechanisms; Toxicity.

\section{Introduction}

Pesticides probably account for the largest amount of chemical substances intentionally released to the environment. An immense quantity of pesticides is applied to fields throughout the world to increase crop production by controlling pests. Pesticides induce physiological responses in pests. Those reactions may harm both target and nontarget organisms, including 
humans (Hernández et al. 2013). Pesticide residues in the environment have therefore received considerable attention based on concerns over their adverse effects on humans and other nontarget species. In many countries, selected pesticides are listed in drinking water standards and guidelines and are intensively monitored in natural waters (García de Llasera and Bernal-González 2001, Nakano et al. 2004), including sources of drinking water (Schipper et al. 2008, Mekonen et al. 2016). Additionally, much effort has been made to remove pesticides during drinking water treatment (Broséus et al. 2009, Nam et al. 2014).

Pesticides undergo both biotic and abiotic degradation after being applied to agricultural fields. During degradation, pesticides are rarely mineralized into carbon dioxide, water, and other inorganic materials; in most cases they are just converted into a number of transformation products (TPs) (Sinclair et al. 2006, Escher and Fenner 2011). Because some TPs are more toxic than their parent pesticides (Martínez Vidal et al. 2009, Fenner et al. 2013), the occurrence of pesticide TPs in natural waters, in particular sources of drinking water, has attracted increasing attention. Intense monitoring of pesticide TPs in natural waters in recent years (Kondo et al. 2012, Reemtsma et al. 2013) has revealed that some pesticide TPs are occasionally present at higher concentrations than their parent pesticides (Hladik et al. 2008, Kameya et al. 2012). Removal of pesticide TPs during drinking water treatment has also attracted attention. Removals are estimated by quantifying and comparing the concentrations in raw and finished waters in full-scale drinking water treatment plants (Coupe and Blomquist 2004) or investigated in laboratory-scale experiments (Gustafson et al. 2003, Hladik et al. 2005).

Most research on pesticide TPs has concerned pesticides applied to upland fields. In contrast, information regarding the removal of TPs derived from pesticides used in rice farming is quite limited. Benner et al. (2013) have reviewed removals via drinking water treatment of many types of micropollutants, including pesticides and their TPs, but only 5 of 23 targeted pesticides were relevant to rice farming. In many countries, especially Asian countries, much agricultural land is used for rice farming. Moreover, rice-farming pesticides tend to enter river water via runoff at higher rates than other pesticides used in upland fields because they are dusted directly over the ponding water of paddy fields and are thus easily released with rainfall runoff or discharges during water-ponding depth control (Matsui et al. 2006), even though the ricefarming pesticides do not generally differ from the upland-filed pesticides in terms of physicochemical properties. Actually, most of the pesticides detected in river water are used in rice farming in Japan, although annual pesticide consumption for upland fields is no less than that for rice paddy fields (Matsui et al. 2002). Hence there is a need for research on the removal of TPs derived from pesticides used in both rice-farming and upland-field agriculture.

Chlorine, which is widely used for disinfection in the final step of drinking water treatment, reacts with inorganic and organic compounds in the water and converts them into a wide variety of by-products. The mutagenicity of raw drinking water is dramatically increased after chlorination (Cheh et al. 1980, Vartiainen and Liimatainen 1986), a clear indication that mutagenic by-products are generated during chlorination. The increase of mutagenicity might be partly due to pesticides in the raw water, because some pesticide solutions have evinced mutagenicity after chlorination although they did not before chlorination (Takanashi et al. 2013). The fact that some pesticide TPs have also increased mutagenicity after chlorination (Takanashi et al. 2014) may partly account for the increase of mutagenicity. From the standpoint of drinking water safety, the mutagenicity of finished 
water must be low, and hence there is a need for a method to remove such pesticides and TPs from water before chlorination.

In this study, we therefore focused on pesticide TPs derived from both upland-field agriculture and rice farming. The objectives of the study were to (1) investigate the removals of 43 compounds (28 TPs and 15 parent pesticides) during steps in drinking water treatment (coagulation-sedimentation, activated carbon adsorption, and ozonation) via laboratory-scale experiments, (2) elucidate the removal mechanisms associated with each process, and (3) discuss whether the processes were effective in reducing mutagenicity derived from TPs and their parent pesticides after chlorination.

\section{Materials and methods}

\subsection{Target compounds and preparation of experimental} raw water

Table 1 lists the target compounds used in the present study. The pesticides were selected so as to cover wide range of physicochemical properties such as $\log K_{\mathrm{OW}}$ from fungicides, herbicides, and insecticides whose TPs were commercially available. The structures of the target compounds are shown in Table S1. The TPs and pesticides were purchased from Wako Pure Chemical Industries (Osaka, Japan), Tokyo Chemical Industry Co., Ltd. (Tokyo, Japan), Cosmo Bio Co., Ltd. (Tokyo, Japan), or Sigma-Aldrich Co. LLC. (Darmstadt, Germany) and used without further purification. Chemical standards of the compounds except diazinon, malathion, malaoxon, diethyl L-(+)-tartrate, and 2aminophenol were dissolved in acetone at $20 \mathrm{mg} / \mathrm{L}$ each to prepare a mixed stock solution for the batch coagulation experiments. Each chemical standard except diazinon, malathion, malaoxon, diethyl L-(+)tartrate, and 2-aminophenol was dissolved in acetone at $20 \mathrm{mg} / \mathrm{L}$ to prepare each stock solution for the batch adsorption and ozonation experiments. Each chemical standard of diazinon, malathion, malaoxon, diethyl L$(+)$-tartrate, and 2-aminophenol was dissolved in MilliQ water (Milli-Q Advantage, Millipore Co., Bedford, MA, USA) at $5,5,50,50$, and $3 \mathrm{mg} / \mathrm{L}$, respectively, which was individually used as each stock solution for all batch experiments.

All experiments were conducted with raw water of a drinking water treatment plant (Moiwa Drinking Water Treatment Plant, Sapporo, Japan) withdrawn from the Toyohira River (Sapporo, Japan) four times (26/10/2012, 15/10/2013, 6/10/2014, and 17/11/2014), and was characterized by a dissolved organic carbon concentration of approximately $1.0 \mathrm{mg}-\mathrm{C} / \mathrm{L}$, turbidity of 1-7 NTU, and alkalinity of approximately $20 \mathrm{mg}$ $\mathrm{CaCO}_{3} / \mathrm{L}$. The river waters withdrawn on $26 / 10 / 2012$ and 15/10/2013 were used for coagulation experiments, that withdrawn on 6/10/2014 was used for ozonation, and that withdrawn on 17/11/2014 was used for powdered activated (PAC) adsorption. We confirmed that none of the target compounds was detected in the river waters. The final concentration of each compound was approximately $10 \mu \mathrm{g} / \mathrm{L}$. To avoid the effect of unintentional carry-over of acetone on coagulation, the acetone was removed from the solution prior to the coagulation experiments by warming the solution at $58^{\circ} \mathrm{C}$ in a water bath. Nitrogen gas was then introduced into the solution for $120 \mathrm{~min}$ to purge out the dissolved acetone. Preliminary studies confirmed that this procedure reduced the dissolved acetone concentration from $500 \mathrm{mg} / \mathrm{L}$ to $10 \mu \mathrm{g} / \mathrm{L}$, the same as the concentration of each target compound. The stock solutions of diazinon, malathion, malaoxon, diethyl L$(+)$-tartrate, and 2-aminophenol were then added to the solution at concentrations of $10 \mu \mathrm{g} / \mathrm{L}$ each because preliminary studies had shown that these compounds volatilized during purging with nitrogen gas. The resulting solution (referred to as experimental raw water) was then used for the batch coagulation experiments. 
Table 1 Target compounds used in the present study.

\begin{tabular}{|c|c|c|c|c|c|c|c|c|c|}
\hline $\begin{array}{l}\text { Parent pesticides } \\
\text { Transformation products } \\
\end{array}$ & \begin{tabular}{|c} 
Measurement \\
method
\end{tabular} & $\begin{array}{c}\text { Monitored } \\
m / z\end{array}$ & $\begin{array}{l}\text { Purchased } \\
\text { from }\end{array}$ & $\begin{array}{r}\text { Remain } \\
\text { after co } \\
\end{array}$ & $\begin{array}{c}\text { ining ration } \\
\text { coagulation } \\
- \\
\end{array}$ & $\begin{array}{c}\text { Remaining ratio } \\
\text { at } 10 \text { min of PAC } \\
\text { contact time }\left(R_{\text {PAC }}\right) \\
- \\
\end{array}$ & $\begin{array}{c}\text { Second order } \\
\text { decomposition rate } \\
\text { constant with } \mathrm{O}_{3}\left(k_{\text {ozone }}\right) \\
k_{\text {ozone }}, \mathrm{M}^{-1} \mathrm{~s}^{-1} \\
\end{array}$ & net rev. $\mu \mathrm{M}^{-1}$ & after PAC ${ }^{\mathrm{e}}$ \\
\hline \multicolumn{10}{|l|}{$\begin{array}{l}\text { Fungicides } \\
\end{array}$} \\
\hline Chlorothalonil & $\mathrm{GC} / \mathrm{MS}$ & 366 & Wako & 0.94 & \pm 0.01 & 0.23 & - & negative $^{c}$ & 0 \\
\hline 1,3-Dicyanobenzene & GC/MS & 128 & Aldrich & 1.21 & & 0.46 & - & $10^{\mathrm{c}}$ & 5 \\
\hline \# Pencycuron & $\mathrm{LC}_{\mathrm{MS}}^{\mathrm{p}}$ & 329.1415 & Wako & 0.99 & \pm 0.01 & $0.15 \pm 0.03$ & $(4.7 \pm 1.9) \times 10^{3}$ & negative $^{\mathrm{d}}$ & 0 \\
\hline \# Phenylurea & $\mathrm{LC}_{\mathrm{MS}}^{\mathrm{p}}$ & 137.0709 & Wako & 0.98 & \pm 0.01 & $0.35 \pm 0.00$ & $(4.9 \pm 1.4) \times 10^{3}$ & negative $^{d}$ & 0 \\
\hline Thiophanate methyl & $\mathrm{LC}_{\mathrm{MS}}{ }^{\mathrm{p}}$ & 343.0529 & Wako & 1.14 & \pm 0.05 & $0.18 \pm 0.03$ & $(3.4 \pm 0.2) \times 10^{4}$ & $380^{\mathrm{b}}$ & 68 \\
\hline 2-Aminobenzimidazole & $\mathrm{LC}_{\mathrm{MS}}^{\mathrm{p}}$ & 134.0713 & Wako & 1.00 & \pm 0.01 & $0.11 \pm 0.03$ & $(1.7 \pm 0.3) \times 10^{4}$ & $260^{b}$ & 30 \\
\hline Methyl-2-benzimidazole cabamate & $\mathrm{LC}_{\mathrm{MS}}^{\mathrm{p}}$ & 192.0768 & Wako & 1.00 & \pm 0.01 & $0.07 \pm 0.02$ & $(6.5 \pm 0.9) \times 10^{3}$ & $410^{\mathrm{b}}$ & 28 \\
\hline \multicolumn{10}{|l|}{ Herbicides } \\
\hline \# Cafenstrole & $\mathrm{LC}_{\mathrm{MS}}^{\mathrm{p}}$ & 351.1485 & Wako & 1.06 & \pm 0.04 & $0.24 \pm 0.01$ & $(1.0 \pm 0.1) \times 10^{3}$ & negative $^{\mathrm{d}}$ & 0 \\
\hline \# 3-(2,4,6-Trimethylphenylsulfonyl)-1,2,4-triazole & $\mathrm{LC}_{\mathrm{MS}}^{\mathrm{p}}$ & 252.0801 & Wako & 0.99 & \pm 0.01 & $0.45 \pm 0.01$ & $(9.4 \pm 2.7) \times 10^{2}$ & negative $^{d}$ & 0 \\
\hline \# Mefenacet & $\mathrm{LC}_{\mathrm{MS}}^{\mathrm{p}}$ & 299.0849 & Wako & 0.99 & \pm 0.00 & $0.10 \pm 0.03$ & $(2.9 \pm 1.0) \times 10^{3}$ & & \\
\hline \# 2(3H)-Benzothiazolone & $\mathrm{LC}_{\mathrm{MS}}^{\mathrm{p}}$ & 152.0165 & Tokyo Chemical & 0.98 & \pm 0.03 & $0.12 \pm 0.01$ & - & $14^{\mathrm{d}}$ & 2 \\
\hline 2-Aminothiophenol & $\mathrm{LC}_{\mathrm{MS}}^{\mathrm{p}}$ & 249.0515 & Tokyo Chemical & 0.97 & \pm 0.01 & $0.07 \pm 0.01$ & $(7.5 \pm 5.7) \times 10^{5}$ & $120^{d}$ & 9 \\
\hline \# Tefuryltrione & $\mathrm{LC}_{\mathrm{MS}}^{\mathrm{p}}$ & 460.1191 & Hayashi & 1.02 & \pm 0.09 & $0.69 \pm 0.03$ & $(2.7 \pm 0.5) \times 10^{3}$ & & \\
\hline \# 2-chlor-4-(methylsulfonyl)-3-[(tetrahydrofiran-2-ylmethoxy)methy]lbenzoic acid & $\mathrm{LC}_{\mathrm{MS}}^{\mathrm{p}}$ & 349.0507 & Hayashi & 1.05 & \pm 0.06 & $0.62 \pm 0.02$ & $(3.5 \pm 2.3) \times 10^{3}$ & & \\
\hline \# Thiobencarb & $\mathrm{GC} / \mathrm{MS}$ & 100 & Wako & 0.97 & \pm 0.01 & 0.23 & - & $81^{\mathrm{a}}$ & 19 \\
\hline \# p-Chlorobenzyl alcohol & GC/MS & 77 & Tokyo Chemical & 1.06 & \pm 0.08 & 0.57 & - & negative $^{\mathrm{b}}$ & 0 \\
\hline \multicolumn{10}{|l|}{ Insecticides } \\
\hline \# Diazinon & $\mathrm{LC}_{\mathrm{MS}}^{\mathrm{p}}$ & 305.1083 & Wako & 1.06 & \pm 0.02 & $0.29 \pm 0.01$ & $(3.4 \pm 0.6) \times 10^{3}$ & $49^{\mathrm{a}}$ & 14 \\
\hline \# 2-Isopropyl-6-methylpyrimidin-4-ol & $\mathrm{LC}_{\mathrm{MS}}^{\mathrm{p}}$ & 153.1022 & Aldrich & 0.98 & \pm 0.02 & $0.51 \pm 0.02$ & $(3.9 \pm 0.5) \times 10^{3}$ & $21^{\mathrm{b}}$ & 11 \\
\hline \# Diazinon oxon & $\mathrm{LC}_{\mathrm{MS}}^{\mathrm{p}}$ & 289.1312 & Wako & 1.03 & \pm 0.01 & $0.40 \pm 0.01$ & $(1.9 \pm 0.6) \times 10^{2}$ & $62^{\mathrm{b}}$ & 25 \\
\hline Diethyl phosphate & $\mathrm{LC}_{\mathrm{MS}}^{\mathrm{p}}$ & 155.0468 & Cosmo & 1.02 & \pm 0.02 & $1.00 \pm 0.02$ & $(1.4 \pm 0.1) \times 10^{2}$ & negative $^{b}$ & 0 \\
\hline Dichlorvos & $\mathrm{LC} \mathrm{MS}^{\mathrm{p}}$ & 220.9532 & Wako & 0.99 & \pm 0.01 & $0.47 \pm 0.11$ & $(5.0 \pm 2.5) \times 10^{3}$ & $20^{\mathrm{a}}$ & 9 \\
\hline Dimethyl phosphate & $\mathrm{LC}_{\mathrm{MS}}^{\mathrm{p}}$ & 127.0155 & Wako & 0.99 & \pm 0.01 & $0.97 \pm 0.06$ & $(4.3 \pm 1.2) \times 10^{1}$ & $5.2^{\mathrm{b}}$ & 5 \\
\hline Disulfoton & GC/MS & 88 & Cosmo & 0.87 & & 0.23 & - & $46^{\mathrm{a}}$ & 11 \\
\hline Disulfoton oxon & GC/MS & 88 & Wako & 0.94 & \pm 0.01 & 0.63 & - & negative $^{\mathrm{b}}$ & 0 \\
\hline Disulfoton sulfoxide & $\mathrm{LC}_{\mathrm{MS}}^{\mathrm{p}}$ & 291.0307 & Cosmo & 0.95 & \pm 0.03 & 0.42 & - & $47^{\mathrm{b}}$ & 20 \\
\hline \# Etofenprox & $\mathrm{GC} / \mathrm{MS}$ & 163 & Wako & 0.29 & \pm 0.01 & 0.19 & $(6.7 \pm 0.6) \times 10^{3}$ & negative $^{\mathrm{d}}$ & 0 \\
\hline$\# \quad$ 2-(4-Ethoxyphenyl)-2-methylpropanol & $\mathrm{LC}_{\mathrm{MS}}^{\mathrm{p}}$ & 212.1645 & Tokyo Chemical & 1.01 & \pm 0.01 & 0.21 & $(1.0 \pm 0.3) \times 10^{4}$ & $78^{\mathrm{d}}$ & 16 \\
\hline \# Fenitrothion & $\mathrm{GC} / \mathrm{MS}$ & 125 & Wako & 0.93 & \pm 0.00 & 0.16 & $(1.2 \pm 0.0) \times 10^{3}$ & $170^{\mathrm{a}}$ & 28 \\
\hline 3-Methyl-4-nitroanisole & $\mathrm{GC} / \mathrm{MS}$ & 150 & Aldrich & 0.99 & \pm 0.01 & $0.06 \pm 0.06$ & $(1.1 \pm 0.9) \times 10^{4}$ & negative $^{\mathrm{b}}$ & 0 \\
\hline 3-Methyl-4-nitrophenol & $\mathrm{LC}_{\mathrm{MS}}{ }^{\mathrm{n}}$ & 152.0353 & Wako & 0.93 & \pm 0.04 & $0.14 \pm 0.00$ & $(2.5 \pm 0.3) \times 10^{4}$ & $2000^{\mathrm{b}}$ & 278 \\
\hline Fenitrooxon & $\mathrm{LC}_{\mathrm{MS}}^{\mathrm{p}}$ & 262.0475 & Wako & 0.96 & \pm 0.02 & $0.12 \pm 0.02$ & $(4.6 \pm 2.6) \times 10^{2}$ & $390^{\mathrm{b}}$ & 45 \\
\hline Methyl paraoxon & $\mathrm{LC}_{\mathrm{MS}}^{\mathrm{p}}$ & 248.0319 & Aldrich & 0.97 & \pm 0.02 & $0.14 \pm 0.01$ & $(5.4 \pm 0.5) \times 10^{2}$ & & \\
\hline$\#$ trimethyl phosphate & $\mathrm{LC}_{\mathrm{MS}}^{\mathrm{p}}$ & 141.0311 & Wako & 0.99 & \pm 0.01 & $0.96 \pm 0.15$ & $(7.0 \pm 2.0) \times 10^{1}$ & negative $^{\mathrm{b}}$ & 0 \\
\hline \# Malathion & $\mathrm{LC}_{\mathrm{MS}}^{\mathrm{p}}$ & 331.0433 & Wako & 1.01 & \pm 0.01 & $0.24 \pm 0.01$ & $(2.8 \pm 0.1) \times 10^{3}$ & $260^{\mathrm{a}}$ & 62 \\
\hline Diethyl fumarate & $\mathrm{GC} / \mathrm{MS}$ & 127 & Wako & 1.08 & \pm 0.00 & 0.60 & - & $17^{\mathrm{b}}$ & 10 \\
\hline Diethyl maleate & GC/MS & 99 & Wako & 0.97 & \pm 0.05 & 0.80 & - & $13^{\mathrm{b}}$ & 10 \\
\hline Diethyl L-(-)-malate & $\mathrm{LC}_{\mathrm{MS}}^{\mathrm{p}}$ & 191.0914 & Wako & 1.14 & \pm 0.02 & $0.43 \pm 0.09$ & $(4.6 \pm 2.3) \times 10^{2}$ & & \\
\hline Diethyl L-(+)-tartrate & $\mathrm{LC}_{\mathrm{MS}}^{\mathrm{p}}$ & 207.0863 & Wako & 0.99 & \pm 0.01 & $0.72 \pm 0.02$ & $(1.9 \pm 0.0) \times 10^{2}$ & $24^{b}$ & 17 \\
\hline \# Malaoxon & $\mathrm{LC}_{\mathrm{MS}}^{\mathrm{p}}$ & 315.0662 & Wako & 1.02 & \pm 0.02 & $0.31 \pm 0.03$ & $(3.4 \pm 1.8) \times 10^{2}$ & negative $^{b}$ & 0 \\
\hline Methidathion & GC/MS & 145 & Wako & 1.01 & \pm 0.02 & 0.39 & - & $51^{\mathrm{a}}$ & 20 \\
\hline Methidathion oxon & $\mathrm{LC} \mathrm{MS}^{\mathrm{p}}$ & 286.9920 & Wako & 0.95 & \pm 0.00 & 0.43 & - & negative $^{c}$ & 0 \\
\hline Pyriproxyfen & GC/MS & 136 & Wako & 0.95 & \pm 0.01 & 0.09 & - & negative $^{d}$ & 0 \\
\hline 4-Phenoxyphenol & GC/MS & 186 & Wako & 1.00 & \pm 0.01 & 0.26 & - & negative $^{\mathrm{d}}$ & 0 \\
\hline
\end{tabular}

$\mathrm{LC} / \mathrm{MS}^{\mathrm{p}}, \mathrm{LC} / \mathrm{MS}$ in positive ion mode; $\mathrm{LC} / \mathrm{MS}{ }^{\mathrm{n}}, \mathrm{LC} / \mathrm{MS}$ in negative ion mode.

Aldrich, Sigma-Aldrich Co. LLC., Darmstadt, Germany; Cosmo, Cosmo Bio Co., Ltd., Tokyo, Japan; Tokyo Chemical, Tokyo Chemical Industry Co., Ltd., Tokyo, Japan; Wako, Wako Pure Chemical Industries, Ltd., Osaka, Japan.

\# Pesticides appricable for rice-farming filed and their TPs.

- Not tested.

a Takanashi, H., Kishida, M., Abiru, K., Kondo, T., Kameya, T., Matsushita, T., Nakajima, T., Ohki, A. (2013) A screening study on the mutagen formation potential of 44 pesticides, Journal of Water Supply Research and Technology-AQUA, 62(1), 14-22

b Takanashi, H., Hama, T., Nakajima, T., Ohki, A., Kondo, T., Kameya, T. and Matsushita, T. (2014) A screening study of mutagen formation potential (MFP) of pesticide transformation products in water environments (PTPWs) to investigate the MFP changes from their parent pesticides through transformations, Journal of Water Environment Technology, 12(1), 25-32.

Takanashi, H., Hama, T., Nakajima, T., Ohki, A., Ueda, T., Matsushita, T., Kondo, T. and Kameya, T. (2016) Quantitative structure-activity relationship of pesticide and their transformation products in water environments to mutagen formation potential, Environmental science, 29, 229-237 (in Japanese).

d This study

e The number of net revertant colonies after chlorination at the concentration which was expected after $1 \mu \mathrm{M}$ of a compound was treated with $10 \mathrm{mg} / \mathrm{L}$ of PAC addition for $10 \mathrm{~min}$, which was calculated from MFP and $R_{\mathrm{PAC}}$.

The batch studies of PAC adsorption and ozonation were conducted individually for each compound. The stock solution of each compound except diazinon, malathion, malaoxon, diethyl L-(+)-tartrate, and 2aminophenol was added to the river water at approximately $10 \mu \mathrm{g} / \mathrm{L}$. Dissolved acetone was purged out from the solution by the same procedure described above to obtain the experimental raw water for the batch adsorption and ozonation experiments. The experimental raw water for diazinon, malathion, malaoxon, diethyl L-(+)-tartrate, and 2-aminophenol was prepared individually by simply adding each stock 
solution to the river water at $10 \mu \mathrm{g} / \mathrm{L}$.

\subsection{Batch coagulation-sedimentation experiments}

Batch coagulation experiments were conducted with 1 $\mathrm{L}$ of the experimental raw water in glass beakers at $20{ }^{\circ} \mathrm{C}$. The $\mathrm{pH}$ of the water was adjusted with aqueous $\mathrm{NaOH}$ to maintain a final $\mathrm{pH}$ of 7.0 after coagulationsedimentation. The water was supplemented with polyaluminum chloride (PACl; 250A, Taki Chemical Co., Ltd., Kakogawa, Japan) at the coagulant dose that had been used in the Moiwa drinking water treatment plant on the day the raw water was sampled (1.0 and $1.4 \mathrm{mg}-\mathrm{Al} / \mathrm{L}$ for the water withdrawn on $15 / 10 / 2013$ and 26/10/2012, respectively). The water was then stirred rapidly for $1 \mathrm{~min}\left(\mathrm{G}=200 \mathrm{~s}^{-1}, 61 \mathrm{rpm}\right)$ and slowly for $10 \mathrm{~min}\left(\mathrm{G}=20 \mathrm{~s}^{-1}, 13 \mathrm{rpm}\right)$. The water was then left at rest for $60 \mathrm{~min}$ to allow the aluminum floc particles that had been generated to settle. Samples were taken from the beaker before coagulant dosing and after settling (supernatant) for quantification of the target compounds. The ratio of the concentrations of each compound after and before sedimentation was used as a metric of the degree of removal via coagulation. The experiments were conducted twice.

\subsection{Batch PAC adsorption experiments}

Batch PAC adsorption experiments were conducted at $20{ }^{\circ} \mathrm{C}$. Five hundred milliliters of each experimental raw water was filtered through a $0.45-\mu \mathrm{m}$ membrane filter (PTFE; Toyo Roshi Kaisha, Ltd., Tokyo, Japan) and then transferred to a 1-L glass vessel. The $\mathrm{pH}$ of the water was adjusted with $\mathrm{HCl}$ to ensure that the final $\mathrm{pH}$ after adsorption was 7.0. The water was supplemented with $10 \mathrm{mg} / \mathrm{L}$ of PAC (median diameter, $18.9 \mu \mathrm{m}$; Taiko W, Futamura Chemical Co., Ltd., Nagoya, Japan) and then stirred with impeller blades at $150 \mathrm{rpm}$. Samples were withdrawn from the vessel at adsorption times of $0,10,20,40$, and $60 \mathrm{~min}$ and filtered through a 0.45 $\mu \mathrm{m}$ membrane filter (PTFE; Toyo Roshi Kaisha) to remove any PAC particles. The concentrations of the target compounds in the filtrates were measured. The ratio of the concentration of each compound remaining at $10 \mathrm{~min}$ of PAC contact time to the concentration before PAC contact $\left(R_{\mathrm{PAC}}\right.$ ) was used as a metric of the removal during PAC adsorption (adsorption rate). This metric was chosen because some compounds reached equilibrium at $20 \mathrm{~min}$ or later but others did not. Therefore, differences in $R_{\mathrm{PAC}}$ did not simply reflect the extent of adsorption rate with PAC after $20 \mathrm{~min}$. The experiments were conducted twice.

\subsection{Batch ozonation experiments}

Batch ozonation experiments were conducted at $20^{\circ} \mathrm{C}$. Five hundred milliliters of each experimental raw water were filtered through a $0.45-\mu \mathrm{m}$ membrane filter and then transferred to a 1-L glass vessel. The $\mathrm{pH}$ of the water was adjusted to 7.0 with $\mathrm{HCl}$. Ozone gas was continuously introduced into the glass vessel at a constant flow rate of $0.3 \mathrm{mg}-\mathrm{O}_{3} /(\mathrm{L} \cdot \mathrm{min})$ via a lab-scale ozone generator (Pretty $\mathrm{O}_{3}$; Metawater Co. Ltd., Tokyo, Japan) while the water was stirred with a magnetic stirrer. Eighty-milliliter samples of the water were withdrawn from the glass vessel at $0,0.5,2,5$, and 15 min. Dissolved $\mathrm{O}_{3}$ was measured in a 20 -milliliter aliquot, and the concentration of the target compound was measured in the remaining $60 \mathrm{~mL}$ after the residual ozone had been quenched with 1.2 stoichiometric equivalents of $\mathrm{Na}_{2} \mathrm{SO}_{3}$. To facilitate comparison of the decomposition of target compounds during ozonation, the second-order decomposition rate constant with ozone $\left(k_{\text {ozone }}\right)$ was calculated for each compound and used as a metric of removal during ozonation. The experiments were conducted twice.

\subsection{Quantification of target compounds with a liquid chromatograph-mass spectrometer \\ The target compounds identified with the "LC/MS" measurement method in Table 1 were quantified via a hybrid quadrupole-orbitrap mass spectrometer (MS; Q- Exactive, Thermo Fisher Scientific Inc., Waltham, MA,}


USA) coupled with a liquid chromatograph system (LC; UltiMate 3000, Thermo Fisher Scientific). A fivemicroliter sample of each solution was assayed with the LC on a $50 \mathrm{~mm} \times 2.1 \mathrm{~mm}$ Hypersil Gold column (1.9$\mu \mathrm{m}$ particle size, Thermo Fisher Scientific). The mobile phase was a binary gradient of $2 \mathrm{mM}$ ammonium formate in Milli-Q water (solvent A) and 100\% methanol (solvent B) at a flow rate of $200 \mu \mathrm{L} / \mathrm{min}$ as follows: for 2-(4-ethoxyphenyl)-2-methylpropanol, 2(3H)-benzothiazolone, 2-aminothiophenol, and 2aminobenzimidazole, 99:1 (v/v) A/B for $2 \mathrm{~min}$, increase linearly to $60 \% \mathrm{~B}$ over a period of $2 \mathrm{~min}$, increase linearly to $75 \% \mathrm{~B}$ over a period of $6 \mathrm{~min}$, increase linearly to $99 \%$ B over a period of $5 \mathrm{~min}$, decrease linearly to $1 \% \mathrm{~B}$ over a period of $0.1 \mathrm{~min}$, and then hold at that ratio for $2.9 \mathrm{~min}$. For the other compounds, 99:1 (v/v) A/B for $1.5 \mathrm{~min}$, increase linearly to $60 \% \mathrm{~B}$ over a period of $1 \mathrm{~min}$, increase linearly to $99 \%$ B over a period of $5.5 \mathrm{~min}$, hold at that ratio for $1.5 \mathrm{~min}$, decrease linearly to $1 \% \mathrm{~B}$ over a period of $0.5 \mathrm{~min}$, and then hold at that ratio for $2 \mathrm{~min}$. The MS was operated in an electrospray ionization mode with a spray voltage of $3.0 \mathrm{kV}$. The temperatures of the capillary and electrospray ionization probe heater were 220 and $450{ }^{\circ} \mathrm{C}$, respectively. The flow rates of the sheath gas, auxiliary gas, and sweep gas were 50, 50, and 50 units, respectively. The S-lens ratio frequency level was set to 78 . Target compounds were quantified in selected-ion-monitoring mode (resolution $=70,000)$. Table 1 shows the relevant ion modes and $\mathrm{m} / \mathrm{z}$ values.

\subsection{Quantification of target compounds with a gas} chromatograph-mass spectrometer

The target compounds identified with the "GC/MS" measurement method in Table 1 were quantified via a gas chromatograph-mass spectrometer (GC/MS; GC, 7890A; MS, 5975C; Agilent Technologies, Inc., Palo Alto, CA, USA) coupled to a capillary column (J\&W DB5-ms; length, $30 \mathrm{~m}$; internal diameter, $0.25 \mathrm{~mm}$; thickness, $0.25 \mu \mathrm{m}$; Agilent Technologies). Before GC/MS analysis, each sample was subjected to solidphase extraction with a Sep-Pak PS2 cartridge (Nihon Waters K. K., Tokyo, Japan) to increase the concentration in acetone by 100 -fold. One microliter of the resulting concentrate was injected into the GC in a splitless mode. The column temperature was controlled as follows: $50^{\circ} \mathrm{C}$ for $2 \mathrm{~min}$, increase linearly to $170{ }^{\circ} \mathrm{C}$ over a period of $12 \mathrm{~min}$, hold at that temperature for 3 min, increase linearly to $200^{\circ} \mathrm{C}$ over a period of $10 \mathrm{~min}$, increase linearly to $300{ }^{\circ} \mathrm{C}$ over a period of $10 \mathrm{~min}$, and then hold at that temperature for $10 \mathrm{~min}$. The temperatures of the ion source and injector were 300 and $220{ }^{\circ} \mathrm{C}$, respectively. Helium at $20 \mathrm{~mL} / \mathrm{min}$ was used as a carrier gas. The measurements were performed in a selected ion-monitoring mode with naphthalene- $\mathrm{d}_{8}$, phenanthrene- $\mathrm{d}_{10}$, anthracene- $\mathrm{d}_{10}, 9$ bromoanthracene, and chrysene- $\mathrm{d}_{12}$ as internal standards. The $m / z$ values used for the quantification of the interests are shown in Table 1.

\subsection{Estimation of partial structures contributing to the extent of removal via PAC adsorption and ozonation}

To identify the partial structures contributing to the extent of removal via PAC adsorption and ozonation, regression analyses were performed between metrics of the removal of the target compounds $\left(R_{\mathrm{PAC}}\right.$ and $\log$ $k_{\text {ozone }}$ for the PAC adsorption and ozonation, respectively) as dependent variables and the numbers of partial structures in the compounds as explanatory variables. First, the number of partial structures was counted via the KAshinhou Tool for Ecotoxicity on Platform for Assessment from Structure (Ministry of the Environment, Government of Japan). Both the dependent and explanatory variables were normalized before the regression analyses. Second, a simple linear regression analysis was performed between the removal metrics and the numbers of partial structures. Descriptors (i.e., partial structures) with $r^{2}>0.1$ were selected. When the variance inflation factor (VIF) 
indicated multicollinearity between any two of the selected descriptors, one of the descriptors was withdrawn (Details of the selection are described in the Results and discussion section). Finally, a multiple linear regression analysis was performed between the removal metric and the remaining descriptors using a step-down procedure.

The octanol/water partition coefficients $\left(\log K_{\text {ow }}\right.$ values) of the target compounds at $\mathrm{pH} 7$ were calculated with Marvin Sketch (ChemAxon, Budapest, Hungary). The energy levels of the highest occupied molecular orbital (HOMO) and the lowest unoccupied molecular orbital (LUMO) of the target compounds were calculated with Winmostar (X-Ability Co. Ltd., Tokyo Japan).

\section{Results and discussion}

\subsection{Coagulation-sedimentation}

The concentrations of almost all compounds tested did not change after coagulation-sedimentation (Table 1, Fig. 1). This result was not surprising because coagulation is an effective way to destabilize small suspended and colloidal particulate matter (Crittenden et al. 2012), but soluble micropollutants such as pesticides and their TPs are not directly associated with suspended and colloidal particulate matter. Our results are consistent with previous reports that most micropollutants are difficult to remove by coagulationsedimentation (Miltner et al. 1989, Hladik et al. 2005, Jiang and Adams 2006, Benner et al. 2013).

Of all the compounds, only etofenprox was removed by coagulation-sedimentation (Table 1). Removal of micropollutants via coagulation-sedimentation has been reported to be governed by adsorption onto natural materials present in the water (Thuy et al. 2008): micropollutants associated with the surfaces of suspended particles and coagulation flocs can be removed during sedimentation, and this mechanism is primarily responsible for micropollutant removal during coagulation-sedimentation (Benner et al. 2013). Hydrophobicity of a compound is therefore a major determinant of the removal efficiency of the compound with coagulation (Thuy et al. 2008). Because etofenprox was the most hydrophobic $\left(\log K_{\text {ow }}\right.$ at $\mathrm{pH} 7$ $=6.3$ ) of the compounds tested, it was the compound most likely to adsorb onto natural particulate matter in the water and to then co-settle with the particulate matter during coagulation. Benner et al. (2013) have reported that hydrophobic chemicals with $\log K_{\mathrm{ow}}$ values of $>6$ can generally be removed during coagulation, in agreement with our results.

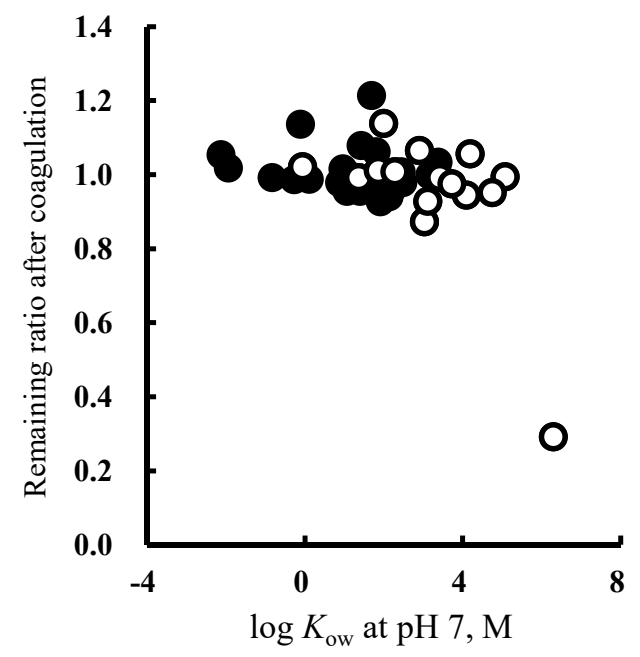

Fig. 1 Relationship between remaining ratio after coagulation and $\log K_{\text {ow }}$ at $\mathrm{pH} 7$. Black and white circles represent TP and parent pesticide, respectively.

\subsection{PAC adsorption}

Values of $R_{\text {PAC }}$ varied widely among compounds, from 0.06 to 1.00 (Table 1 ). $R_{\text {PAC }}$ was weakly and negatively correlated $\left(r^{2}=0.40\right)$ to $\log K_{\text {ow }}$ at $\mathrm{pH} 7$ : the lower the $\log K_{\mathrm{ow}}$, the higher the $R_{\mathrm{PAC}}$ (Fig. 2). Nonpolar compounds have a tendency to adsorb more strongly to nonpolar adsorbents such as activated carbon (Crittenden et al. 2012), in agreement with our results. No substantial difference was observed between the rice-farming and the upland-field pesticides (Fig. S1).

The TPs (black circles, Fig. 2) seemed to be more 

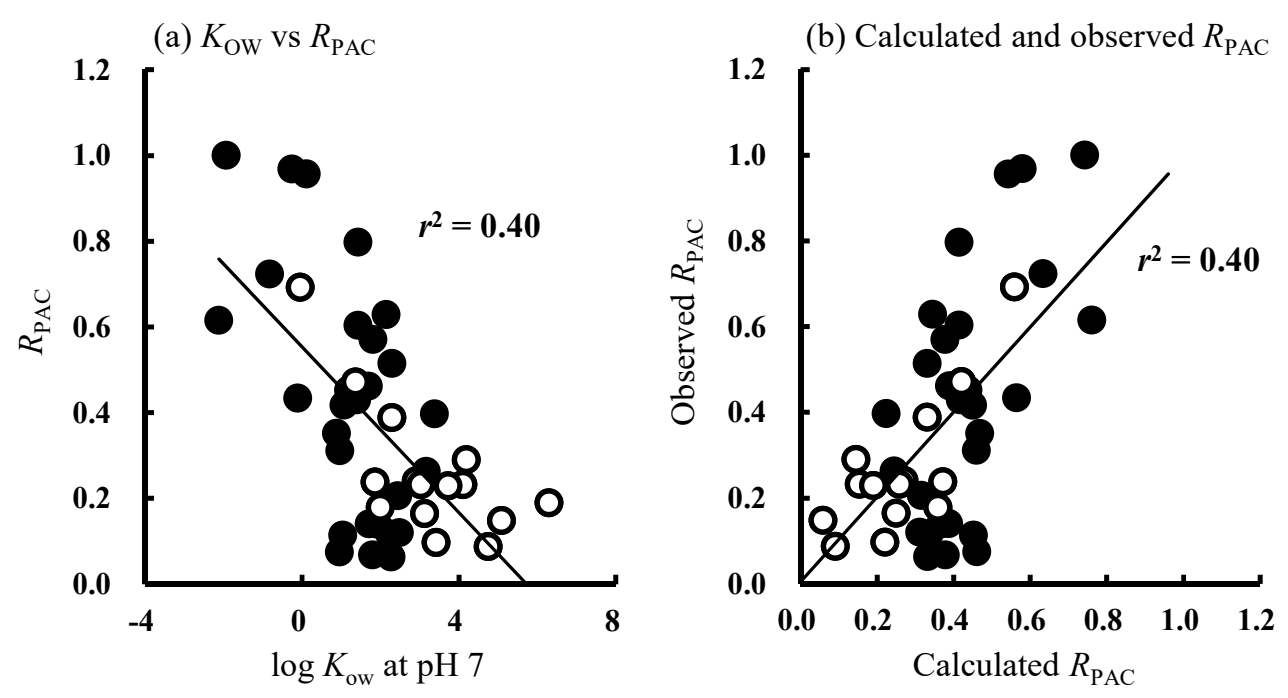

Fig. 2 (a) Relationship between remaining ratio at $10 \mathrm{~min}$ of PAC adsorption $\left(R_{\mathrm{PAC}}\right)$ and $\log K_{\text {ow }}$ at $\mathrm{pH}$ 7. (b) Comparison between the calculated and observed $R_{\mathrm{PAC}}$ values. Black and white circles represent TP and parent pesticide, respectively.

difficult to remove via PAC adsorption than their parent pesticides (white circles). The $R_{\text {PAC }}$ ratios of five TPs and their parent pesticides were roughly the same $\left(0.8_{-}\right.$ 1.2, Fig. 3), but 18 TPs were more difficult to remove via PAC adsorption than their parent pesticides $\left(R_{\mathrm{PAC}}>\right.$ 1.2). Only five TPs were easier to remove via PAC adsorption than their parent pesticides $\left(R_{\mathrm{PAC}}<0.8\right)$. Gustafson et al. (2003) have also reported the same pattern. A TP is typically more polar than its parent compound (Benner et al. 2013, Fenner et al. 2013). The decrease of adsorptive removal due to transformations in the environment was most likely associated with a decrease of hydrophobicity from the parent pesticides to the TPs.

The group of TPs that were most difficult to remove via PAC adsorption included diethyl phosphate $\left(R_{\mathrm{PAC}}=\right.$ $1.00)$, dimethyl phosphate $\left(R_{\mathrm{PAC}}=0.97\right)$, and trimethyl phosphate $\left(R_{\mathrm{PAC}}=0.96\right)$. These TPs may be generated in the environment from the organophosphorus insecticides diazinon (Ibanez et al. 2006), dichlorvos (Benoit-Marquié et al. 2004), and fenitrothion (Durand et al. 1992), respectively, although their parent pesticides were more efficiently removed via PAC adsorption (Table 1). That these TPs are very hydrophilic ( $\log K_{\mathrm{ow}}<0.1$ at $\left.\mathrm{pH} 7\right)$ most likely reduced

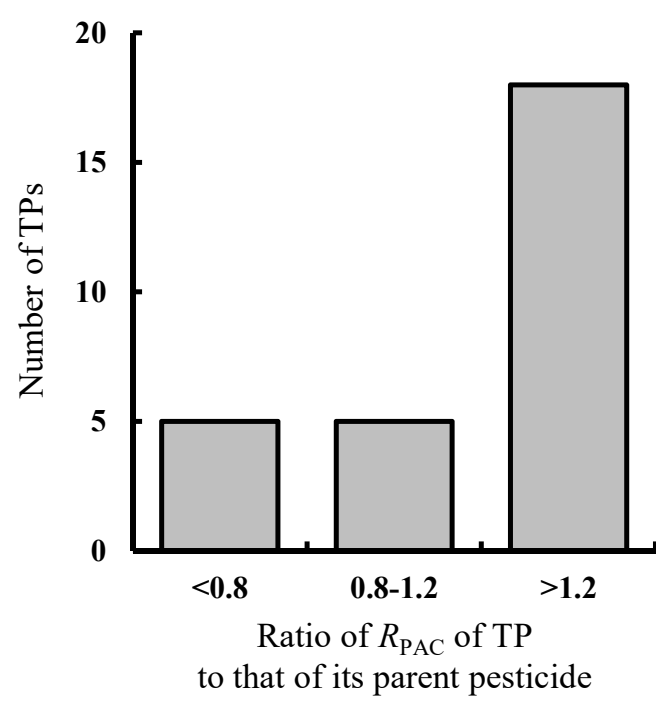

Fig. 3 Comparison of $R_{\mathrm{PAC}}$ between TP and its parent pesticide.

their removability via PAC adsorption. The second group ranked by difficulty of removal included diethyl maleate $\left(R_{\mathrm{PAC}}=0.80\right)$, diethyl L- $(+)$-tartrate $\left(R_{\mathrm{PAC}}=\right.$ $0.72)$, and tefuryltrione $\left(R_{\mathrm{PAC}}=0.69\right)$. Diethyl maleate and diethyl L-(+)-tartrate are reportedly photodegradation products of the organophosphorus insecticide malathion (Bavcon Kralj et al. 2007) and have very low $\log K_{\text {ow }}$ values at $\mathrm{pH} 7$ ( -1.2 and -0.7 , respectively). Unlike diethyl maleate and diethyl L-(+)tartrate, tefuryltrione is a herbicide, not a TP. Tefuryltrione $\left(\log K_{\mathrm{ow}}=0.0\right.$ at $\left.\mathrm{pH} 7\right)$ was the parent pesticide that was least removable via PAC adsorption 
(a) $\log K_{\mathrm{ow}}$ at $\mathrm{pH} 7$ and HOMO

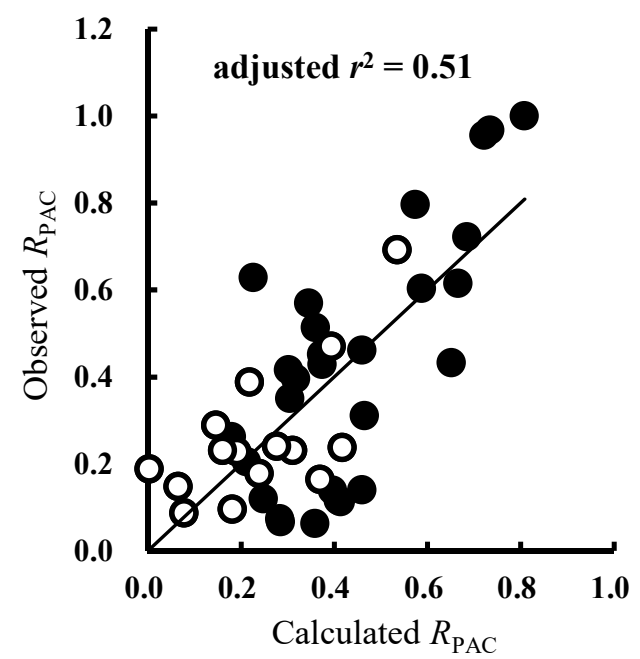

(b) $\log K_{\mathrm{ow}}$ at $\mathrm{pH} 7$ and LUMO

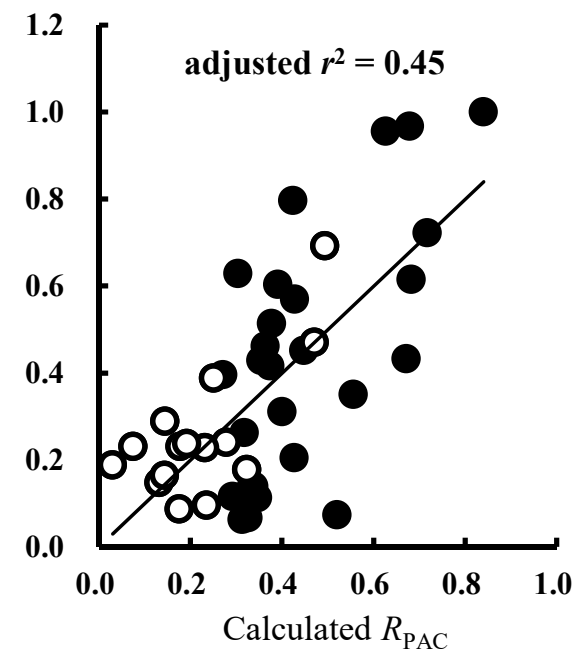

Fig. 4 Comparison between the calculated and observed $R_{\mathrm{PAC}}$ values (remaining ratios after 10 min of PAC adsorption). Regression analysis was conducted with explanatory variables (a) $\log K_{\text {ow }}$ at $\mathrm{pH} 7$ and energy level of HOMO and (b) $\log K_{\text {ow }}$ at pH 7 and energy level of LUMO. Black and white circles represent TP and parent pesticide, respectively.

in the present study. The recent increase of tefuryltrione use and its low acceptable daily intake suggest that tefuryltrione should be monitored in drinking water and source waters (Kamata et al. 2017).

Lin and Xing (2008) reported that the extent of adsorption of phenolic compounds to carbon nanotubes was in the order of phenol $<$ catechol $<$ pyrogallol, even though their $\log K_{\text {ow }}$ were in the same order. They concluded that the increase in the extent of adsorption was due to the increased strength of $\pi-\pi$ interactions between the phenolic compounds and the graphene surface. A similar tendency has been reported in adsorption of chlorophenols to granular activated carbon by Hamdaoui and Naffrechoux (2007). The graphene surface is highly polarizable, and it accordingly has the potential to act as an adsorbent that attracts $\pi$-acceptors and $\pi$-donors to the electron-rich graphene surface area near edges and to the relatively electron-poor central regions, respectively (Lin and Xing 2008). One electron is transferred from the HOMO of the graphene surface to the LUMO of the adsorbate molecule in the former case; one electron is transferred from the HOMO of the adsorbate molecule to the LUMO of the graphene surface in the latter case. These electron transfers are presumed to enhance the $\pi$ $\pi$ interactions between the adsorbate and the graphene surface. Greater adsorption of an adsorbate is therefore expected when the transfer of the electron between the adsorbate and the graphene surface is most exergonic. This conclusion suggests that the residual errors in the regression analysis between $R_{\mathrm{PAC}}$ and $\log K_{\mathrm{ow}}$ might be explained by $\pi-\pi$ interactions. When the energy level of the LUMO was added to the regression analysis between $R_{\text {PAC }}$ and $\log K_{\text {ow }}$ as an explanatory variable, the $r^{2}$ increased from 0.40 to 0.45 (Figs. 2 and $4 \mathrm{~b}$ ). When the energy level of the HOMO was added to the regression analysis, the $r^{2}$ increased even further to 0.51 . These results are consistent with our hypothesis that the $\pi-\pi$ electron donor-acceptor interactions account in part for the extent of adsorptive removal. In addition, the change of the increase of the $r^{2}$ value from 0.45 to 0.51 suggests that the graphene surface of the activated carbon used in this study probably acted as an acceptor of electrons from the target compounds rather than as a donor of electrons to them.

To identify the partial structures that contributed to the 
Table 2 Results of multiple linear regression analysis of removal via PAC adsorption $\left(R_{\mathrm{PAC}}\right.$, remaining ratio at $10 \mathrm{~min}$ of adsorption).

\begin{tabular}{lccc}
\hline Descriptor & Standard partial regression coefficient $(\beta)$ & $t$-value & $p$-value \\
\hline \hline Aromatic rings & -0.13 & -4.64 & $<0.01$ \\
- & 0.10 & 3.74 & $<0.01$ \\
$-\mathrm{OH}$ bonded with heteroatoms & -0.08 & -2.98 & $<0.01$ \\
$-\mathrm{NO}_{2}$ bonded with aromatic rings & & & \\
\hline
\end{tabular}

extent of removal during PAC adsorption, regression analyses were performed on $R_{\mathrm{PAC}}$ and the number of partial structures in the target compounds. Among the 134 descriptors of the partial structures, 11 (-NO2 [\$ aromatics], aromatic c- $\mathrm{NO}_{2}$, fatty $\mathrm{NO}_{2}$, aromatic atom, aromatics, heteroatom- $\mathrm{OH}$, fatty $\mathrm{C}-\mathrm{OR}$, fatty $\mathrm{C}-$ $\mathrm{PO}_{4}$, benzene, fused aroma, and $\mathrm{P}=\mathrm{O}$ ) were selected as partial structures that might be related to the adsorbability of the compounds tested. This hypothesis was tested via simple linear regression analysis. However, multicollinearity (VIF > 15) was detected between any two of the descriptors "- $\mathrm{NO}_{2}$ [\$ aromatics]", "aromatics c- $\mathrm{NO}_{2}$ ", and "fatty $\mathrm{NO}_{2}$ ", as well as between "aromatic atom" and "aromatics". Each of the compounds selected to have " $-\mathrm{NO}_{2}$ [\$ aromatics]", "aromatics c- $\mathrm{NO}_{2}$ ", and "fatty $\mathrm{NO}_{2}$ " had the same partial structure: a $-\mathrm{NO}_{2}$ moiety bonded to an aromatic ring. The developer of the software used in this study had not released the definition of each descriptor at the time of the study. For the further regression analysis, we nevertheless assumed the descriptor "aromatics $\mathrm{c}-\mathrm{NO}_{2}$ " to be an indicator of the partial structure "- $\mathrm{NO}_{2}$ bonded with aromatic rings". The descriptor "aromatic atom" was the number of atoms contained in aromatic rings, whereas the descriptor "aromatics" was the number of aromatic rings; both of these descriptors were metrics of the number of aromatic rings. Accordingly, we selected the descriptor "aromatics" as a representative of the partial structure "aromatic rings" for further regression analysis. After addressing the issues associated with multicollinearity, we selected eight descriptors as partial structures that might be related to the adsorbability of the compounds (VIF $<3$ ). Further multiple linear regression analysis in accord with a step-down procedure suggested that three descriptors (aromatics, heteroatom- $\mathrm{OH}$, and aromatics c- $\mathrm{NO}_{2}$ ) were related to adsorbability (Table 2 ). The adjusted $r^{2}$ of the multiple regression was 0.57 . The significance probabilities ( $p$ values) of the descriptors were 0.00 , the indication being that the standard partial regression coefficients were appropriate. Among the descriptors, the descriptor "aromatic rings" had the largest absolute value of the standard partial regression coefficient $\beta$, but the value of $\beta(-0.13)$ was not large in magnitude. The negative value of $\beta$ suggested that the compounds with aromatic rings might have tended to be removed more easily by PAC adsorption. Lin and Xing (2008) have reported that the adsorption affinity of a compound to carbon nanotubes increases with increasing number of aromatic rings of the compound, a conclusion consistent with our results.

\subsection{Ozonation}

The second-order decomposition rate constant with ozone varied from 43 to $750,000 \mathrm{M}^{-1} \mathrm{~s}^{-1}$ among the compounds tested (Table 1). The rate constant was positively correlated with the energy level of the HOMO $\left(r^{2}=0.59\right)$ (Fig. 5). Oxidation is a major chemical reaction expected in ozonation: an electron is transferred from the HOMO of the compound to the LUMO of ozone (or other oxidants such as the hydroxyl radical). Accordingly, the higher the energy level of the HOMO of a compound is, the more easily the electron is transferred from the compound to an ozone molecule, the result being more rapid oxidation. 


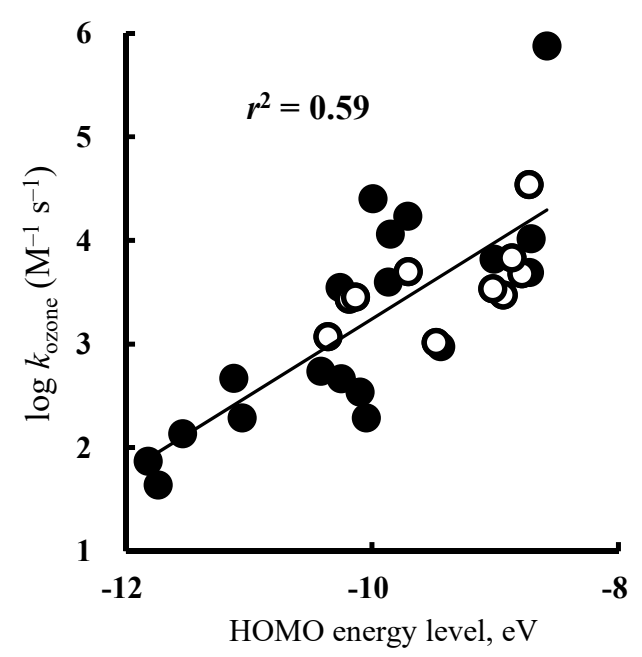

Fig. 5 Relationship between logarithm of second-order decomposition rate constant with ozone (log $\left.k_{\text {ozone }}\right)$ and HOMO energy level. Black and white circles represent TP and parent pesticide, respectively.

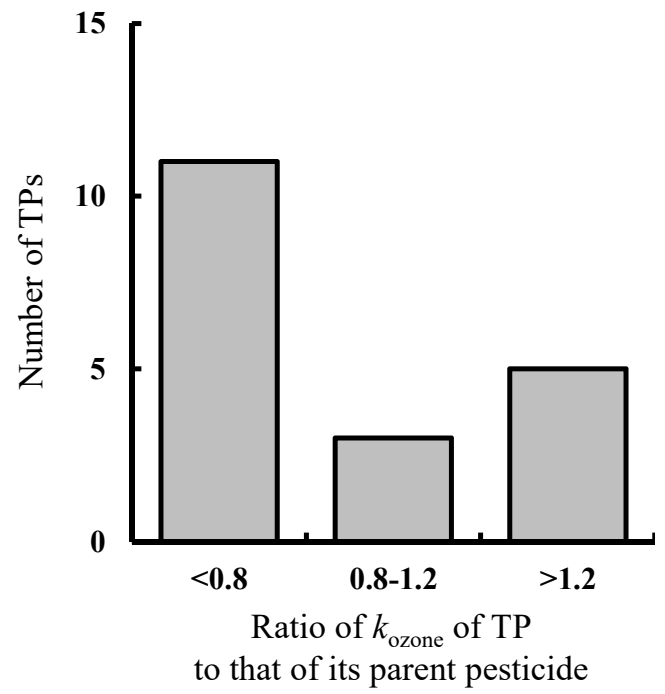

Fig. 6 Comparison of $k_{\text {ozone }}$ between TP and its parent pesticide.

Other researchers have reported the same pattern $\mathrm{CHu}$ et al. 2000, Kušić et al. 2009). Most of the TP decomposition rate constants (black circles, Fig. 5) were smaller than those of their parent pesticides (white circles). The decomposition rate constants of 11 of the TPs investigated in this study were less than $80 \%$ of the decomposition rate constants of their parent pesticides (Fig. 6); the decomposition rate constants of five of the TPs exceeded the decomposition rate constants of their parent pesticides by more than 20\%. These observations suggest that the pesticides became resistant to decomposition by ozone after undergoing transformations in the environment. No substantial difference was observed between the rice-farming and the upland-field pesticides (Fig. S1).

To identify partial structures that contributed to decomposition with ozone, regression analyses were performed on $\log k_{\text {ozone }}$ versus the numbers of partial structures in the target compounds. Among the 134 descriptors of partial structures, simple linear regression analysis identified 20 descriptors (aromatic $\mathrm{c}-\mathrm{NH}_{2}$, aniline single, amine $\mathrm{S}$ (aromatics), aromatic thiol, thiophenol, aromatic c-SH, all $\mathrm{SH}$ for classes, fatty $\mathrm{P}$, phosphorus $[\mathrm{P}]$, aromatics, aromatic atom, $-\mathrm{N}$ [ $\$$ aromatic], $\mathrm{P}=\mathrm{O}$, fatty $\mathrm{N} \mathrm{NO}$, fatty $\mathrm{O}$, aniline, heteroatom- $\mathrm{OH}$, heteroatom- $\mathrm{OMe}$, fatty $\mathrm{C}-\mathrm{PO}_{4}$, and benzene) of partial structures of the compounds tested that might have been related to the extent of decomposition with ozone. Because multicollinearity (VIF > 15) was detected between any two of the descriptors "aromatic c-NH${ }_{2}$ ", "aniline single", and "amine S (aromatics)", we selected the descriptor "aromatic c- $\mathrm{NH}_{2}$ " as representative of compounds having a $-\mathrm{NH}_{2}$ moiety bonded to an aromatic ring. The descriptors "aromatic thiol", "thiophenol", "aromatic c$\mathrm{SH}^{2}$, and "all SH for classes" had large VIF values (>15); from among these, the descriptor "aromatic c$\mathrm{SH}^{\prime \prime}$ was selected as representative of compounds having a $-\mathrm{SH}$ moiety bonded to an aromatic ring. The descriptor "fatty $\mathrm{P}$ " was selected, but the descriptor "phosphorus [P]" was withdrawn; and the descriptor "aromatics" was selected, but the descriptor "aromatic atom" was withdrawn. After the selection based on multicollinearity, 11 descriptors were selected (VIF < 7). One of the descriptors was either "- $\mathrm{NH}_{2}$ bonded with aromatic rings" or "-SH bonded with aromatic rings" because in this study compounds having $-\mathrm{NH}_{2}$ groups bonded with aromatic rings had - $\mathrm{SH}$ groups bonded with aromatic rings, and we could not distinguish the effect of these two groups on the extent 
Table 3 Results of multiple linear regression analysis of decomposition with ozone (log $k_{\text {ozone, }}$ second-order decomposition rate constant with $\mathrm{O}_{3}$ ).

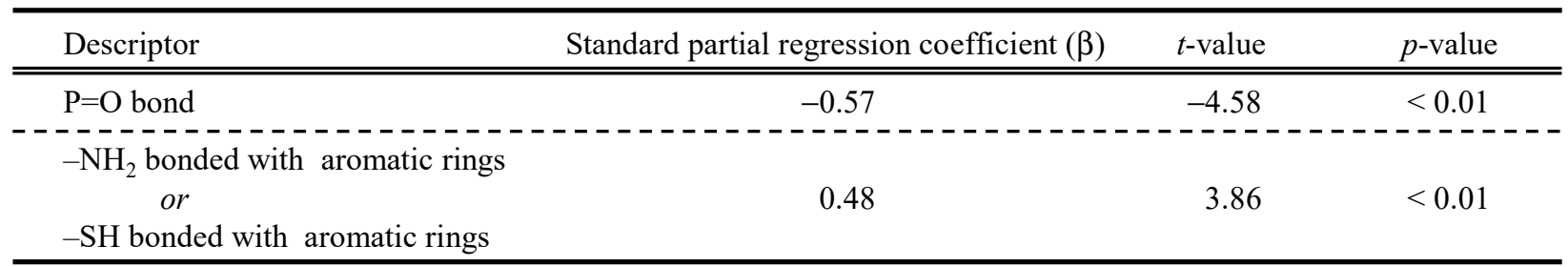

of decomposition with ozone. Further multiple linear regression analysis with the step-down procedure suggested that three descriptors $\left(\mathrm{P}=\mathrm{O}\right.$, aromatic $\mathrm{c}-\mathrm{NH}_{2}$, and aromatic $\mathrm{c}-\mathrm{SH}$ ) were related to the extent of decomposition with ozone (Table 3 ). The adjusted $r^{2}$ of the multiple regression was 0.58 . The very small $p$ values $(0.00)$ associated with both descriptors indicated that the standard partial regression coefficients were significantly different from zero.

The descriptor " $\mathrm{P}=\mathrm{O}$ bond" had a large negative standard partial regression coefficient $(\beta=-0.57)$, the suggestion being that compounds with $\mathrm{P}=\mathrm{O}$ bonds tended to be more difficult to decompose with ozone. The phosphoryl group, which includes a $\mathrm{P}=\mathrm{O}$ bond, acts as an electron acceptor because of the electronegativity of the P atom (Baumgartner 2014). In general, compounds that have electron-donor substituents degrade rapidly in oxidation processes, whereas those having electron-acceptor groups degrade slowly (von Gunten 2003, Kušić et al. 2009). Accordingly, compounds with $\mathrm{P}=\mathrm{O}$ bonds likely tended to react more difficult to decompose with ozone. The descriptor either "- $\mathrm{NH}_{2}$ bonded with aromatic" or "-SH bonded with aromatic rings" had a large positive standard partial regression coefficient $(\beta=0.48)$, the suggestion being that compounds with either thiol or amino groups tended to be more easily decomposed with ozone. Because both $-\mathrm{NH}_{2}$ (Kušić et al. 2009) and -SH (Bocci 2006) are electron-donor groups, compounds with these functional groups were expected to react rapidly with ozone. Actually, von Gunten (2003) has reported that compounds containing amino groups are effectively oxidized by ozone, and those with thiol groups also react rapidly with ozone. Our results are consistent with these observations, but the present study did not reveal whether the thiol or amino group enhanced the extent of decomposition with ozone.

\subsection{Mutagenicity formation potential of compounds} difficult to remove by coagulation-sedimentation and PAC adsorption

If a compound is removed from the aqueous phase by entrapment in flocs during coagulation or by adsorption onto PAC particles, it will not contact chlorine, which is applied to the water in the final disinfection process. The mutagenicity of the compound potentially caused by chlorination can therefore be decreased simply by coagulation or adsorption onto PAC. In contrast, during the ozonation process, a compound is oxidized and then transformed into other by-products that are still present in the aqueous phase, and the resulting by-products accordingly contact chlorine. Whether the mutagenicity associated with the compound increases or decreases after subsequent chlorination therefore depends on the compounds generated during ozonation and is not simply explained by the disappearance of the compound. Actually, Matsushita et al. (2016) have reported that a pre-ozonation process increased the mutagenicity of a solution containing the X-ray contrast medium iopamidol after chlorination, even though iopamidol itself completely disappeared during the pre-ozonation step. We therefore investigated the effectiveness of coagulation-sedimentation and PAC adsorption in reducing potential mutagenicity after 
subsequent chlorination by using mutagenicity formation potential (MFP) (Takanashi et al. 2013, Takanashi et al. 2014, Takanashi et al. 2016) as an index of toxicity induced after chlorination. The investigation did not address the effectiveness of ozonation.

As mentioned in section 3.1, the only compound removed in the coagulation process was etofenprox. Several compounds were difficult to remove even via PAC adsorption (section 3.2). Diethyl phosphate, dimethyl phosphate, and trimethyl phosphate were among the compounds most difficult to remove; diethyl maleate, diethyl L-(+)-tartrate, and tefuryltrione were in the group next most difficult to remove. However, diethyl phosphate and trimethyl phosphate did not induce mutagenicity after chlorination, and the MFPs of dimethyl phosphate (5.2 net revertant colonies [net rev.] $\mu \mathrm{M}^{-1}$ ), diethyl maleate (13 net rev. $\mu \mathrm{M}^{-1}$ ) and diethyl L-(+)-tartrate (24 net rev. $\mu \mathrm{M}^{-1}$ ) were relatively small among the compounds tested in the present study (Table 1). The implication is that possible health effects related to the induction of gene mutation would be small, even though these compounds are found in tap water. In contrast, the MFP of tefuryltrione has not yet been reported, but chlorination completely transforms tefuryltrione into 2-chloro-4-(methylsulfonyl)-3[(tetrahydrofuran-2-ylmethoxy)methyl]benzoic acid (CMTBA) (Kamata et al. 2017), and CMTBA is reportedly very stable during chlorination (Kamata et al. 2017). Because CMTBA does not induce mutagenicity (Food Safety Commission Government of Japan 2009), the MFP of tefuryltrione is expected to be negative.

Among the compounds tested in the present study, seven had very high MFPs that exceeded 100 net rev. $\mu \mathrm{M}^{-1}$. These compounds included 3-methyl-4nitrophenol, which may be produced in the environment, is a major TP of the organophosphorus insecticide fenitrothion (Misra et al. 1993, Matsushita et al. 2006), and had the largest MFP of 2000 net rev. $\mu \mathrm{M}^{-1}$. However, each of the seven compounds was effectively removed via PAC adsorption $\left(R_{\mathrm{PAC}}<0.24\right)$. Overall, PAC adsorption appeared to be an effective treatment for the reduction of potential mutagenicity caused by chlorination, not only for the parent pesticides but also for their TPs.

\section{Conclusions}

1. Coagulation-sedimentation was ineffective in removing all compounds (28 TPs and 14 parent pesticides) tested in the present study, with the exception of the most hydrophobic pesticide, etofenprox.

2. Removal via PAC adsorption correlated positively with $\log K_{\text {ow }}$ values at $\mathrm{pH} \mathrm{7,} \mathrm{the} \mathrm{indication} \mathrm{being}$ that relatively polar compounds were more difficult to remove via PAC adsorption. Removal correlated positively with the energy level of the HOMO, the suggestion being that the graphene surface of PAC particles likely acts as an acceptor of electrons from the target compounds, and electron transfer may enhance the strength of the $\pi-\pi$ interactions between the adsorbates and the graphene surface. Multiple linear regression analysis between the extent of removal and the partial structures of the target compounds suggested that the compounds with aromatic rings tended to be more easily removed via PAC adsorption.

3. Removal via ozonation correlated positively with the energy level of the HOMO, probably because compounds with a relatively high energy level HOMO could more easily transfer an electron to the LUMO of ozone or other oxidants such as hydroxyl radicals. Multiple linear regression analyses suggested that compounds with $\mathrm{P}=\mathrm{O}$ bond and $-\mathrm{NH}_{2}$ or $-\mathrm{SH}$ groups tended to be easily decomposed by ozone.

4. The parent pesticides tested in this study tended to 
become more difficult to remove via both PAC adsorption and ozonation after transformation into their TPs in the environment.

5. The compounds that were difficult to remove via PAC adsorption did not induce strong mutagenicity after chlorination, and the compounds that induced strong mutagenicity after chlorination could be removed by PAC adsorption. PAC adsorption is therefore likely to be an effective way to reduce the potential mutagenicity caused by chlorination, not only for the parent pesticides but also for their TPs.

\section{Acknowledgements}

This research was supported in part by a Grant-in-Aid for Scientific Research S (16H06362) from the Japan Society for the Promotion of Science and by the Environment Research and Technology Development Fund (5B-1104) of the Ministry of the Environment, Japan.

\section{References}

Baumgartner, T. (2014) Insights on the design and electron-acceptor properties of conjugated organophosphorus materials. Accounts of Chemical Research 47(5), 1613-1622.

Bavcon Kralj, M., Černigoj, U., Franko, M. and Trebše, P. (2007) Comparison of photocatalysis and photolysis of malathion, isomalathion, malaoxon, and commercial malathion-Products and toxicity studies. Water Research 41(19), 4504-4514.

Benner, J., Helbling, D.E., Kohler, H.-P.E., Wittebol, J., Kaiser, E., Prasse, C., Ternes, T.A., Albers, C.N., Aamand, J., Horemans, B., Springael, D., Walravens, E. and Boon, N. (2013) Is biological treatment a viable alternative for micropollutant removal in drinking water treatment processes? Water Research 47(16), 5955-5976.

Benoit-Marquié, F., de Montety, C., Gilard, V., Martino, R., Maurette, M.T. and Malet-Martino, M. (2004) Dichlorvos degradation studied by 31P-NMR.
Environmental Chemistry Letters 2(2), 93-97.

Bocci, V.A. (2006) Scientific and medical aspects of ozone therapy. State of the art. Archives of Medical Research 37(4), 425-435.

Broséus, R., Vincent, S., Aboulfadl, K., Daneshvar, A., Sauvé, S., Barbeau, B. and Prévost, M. (2009) Ozone oxidation of pharmaceuticals, endocrine disruptors and pesticides during drinking water treatment. Water Research 43(18), 4707-4717.

Cheh, A., Skochdopole, J., Koski, P. and Cole, L. (1980) Nonvolatile mutagens in drinking water: production by chlorination and destruction by sulfite. Science 207(4426), 90-92.

Coupe, R.H. and Blomquist, J.D. (2004) Water-soluble pesticides in finished water of community water supplies. Journal AWWA 96(10), 56-68.

Crittenden, J.C., Trussell, R.R., Hand, D.W., Howe, K.J., Tchobanoglous, G. and Borchardt, J.H. (2012) MWH's Water Treatment: Prinsiples and Design, John Wiely \& Sons, Inc., Hoboken, NJ, USA.

Durand, G., Mansour, M. and Barceló, D. (1992) Identification and determination of fenitrothion photolysis products in water-methanol by gas chromatography - mass spectrometry. Analytica Chimica Acta 262(1), 167-178.

Escher, B.I. and Fenner, K. (2011) Recent advances in environmental risk assessment of transformation products. Environmental Science \& Technology 45(9), 3835-3847.

Fenner, K., Canonica, S., Wackett, L.P. and Elsner, M. (2013) Evaluating pesticide degradation in the environment: blind spots and emerging opportunities. Science 341(6147), 752-758.

Food Safety Commission Government of Japan (2009) Risk Assessment Reports of Pesticides; Tefuryltrione.

https://www.env.go.jp/council/10dojo/y10416/ref04.pdf, in Japanese (accessed on 6 July 2017). García de Llasera, M.P. and Bernal-González, M. (2001) Presence of carbamate pesticides in 
environmental waters from the northwest of Mexico: determination by liquid chromatography. Water Research 35(8), 1933-1940.

Gustafson, D.I., Carr, K.H., Carson, D.B., Fuhrman, J.D., Hackett, A.G., Hoogheem, T.J., Snoeyink, V.L., Curry, M., Heijman, B., Chen, S., Hertl, P. and van Wesenbeeck, I. (2003) Activated carbon adsorption of chloroacetanilide herbicides and their degradation products from surface water supplies. Journal of Water Supply: Research and Technology - Aqua 52(6), 443-454.

Hamdaoui, O. and Naffrechoux, E. (2007) Modeling of adsorption isotherms of phenol and chlorophenols onto granular activated carbon. Journal of Hazardous Materials 147(1), 381-394.

Hernández, A.F., Parrón, T., Tsatsakis, A.M., Requena, M., Alarcón, R. and López-Guarnido, O. (2013) Toxic effects of pesticide mixtures at a molecular level: Their relevance to human health. Toxicology 307(Supplement C), 136-145.

Hladik, M.L., Roberts, A.L. and Bouwer, E.J. (2005) Removal of neutral chloroacetamide herbicide degradates during simulated unit processes for drinking water treatment. Water Research 39(20), 5033-5044.

Hladik, M.L., Bouwer, E.J. and Roberts, A.L. (2008) Neutral degradates of chloroacetamide herbicides: Occurrence in drinking water and removal during conventional water treatment. Water Research 42(20), 4905-4914.

Hu, J.-y., Morita, T., Magara, Y. and Aizawa, T. (2000) Evaluation of reactivity of pesticides with ozone in water using the energies of frontier molecular orbitals. Water Research 34(8), 2215-2222.

Ibanez, M., Sancho, J.V., Pozo, O.J. and Hernandez, F. (2006) Use of liquid chromatography quadrupole time-of-flight mass spectrometry in the elucidation of transformation products and metabolites of pesticides. Diazinon as a case study. Anal Bioanal Chem 384(2), 448-457.
Jiang, H. and Adams, C. (2006) Treatability of chloros-triazines by conventional drinking water treatment technologies. Water Research 40(8), 1657-1667.

Kamata, M., Asami, M. and Matsui, Y. (2017) Presence of the $\beta$-triketone herbicide tefuryltrione in drinking water sources and its degradation product in drinking waters. Chemosphere 178, 333-339.

Kameya, T., Saito, M., Kondo, T., Toriumi, W., Fujie, K., Matsushita, T. and Takanashi, H. (2012) Detection of fenitrothion and its degradation product 3-methyl-4-nitrophenol in water environment. Journal of Water and Environment Technology 10(4), 427-436.

Kondo, T., Saito, M., Kameya, T., Fujie, K., Matsushita, T. and Takanashi, H. (2012) Analytical method for simultaneous determination of pesticides and pesticide transformation products in water environment using GC-MS and LC-MS/MS. Journal of Water and Environment Technology 10(4), 409417.

Kušić, H., Rasulev, B., Leszczynska, D., Leszczynski, J. and Koprivanac, N. (2009) Prediction of rate constants for radical degradation of aromatic pollutants in water matrix: A QSAR study. Chemosphere 75(8), 1128-1134.

Lin, D. and Xing, B. (2008) Adsorption of phenolic compounds by carbon nanotubes: role of aromaticity and substitution of hydroxyl groups. Environmental Science \& Technology 42(19), 7254-7259.

Martínez Vidal, J.L., Plaza-Bolaños, P., RomeroGonzález, R. and Garrido Frenich, A. (2009) Determination of pesticide transformation products: A review of extraction and detection methods. Journal of Chromatography A 1216(40), 6767-6788.

Matsui, Y., Itoshiro, S., Buma, M., Matsushita, T., Hosogoe, K., Yuasa, A., Shinoda, S. and Inoue, T. (2002) Predicting pesticide concentrations in river water with a hydrologically calibrated basin-scale runoff model. Water Science and Technology 45(9), $141-148$. 
Matsui, Y., Narita, K., Inoue, T. and Matsushita, T. (2006) Screening level analysis for monitoring pesticide in river water using a hydrological diffuse pollution model with limited input data. Water Science and Technology 53(10), 173-181.

Matsushita, T., Matsui, Y. and Matsui, Y. (2006) Estimating mutagenic compounds generated during photolysis of fenitrothion-by HPLC fractionation followed by mutagenicity testing and highresolution GC-MS analysis. Chemosphere 64(1), 144-151.

Matsushita, T., Hashizuka, M., Kuriyama, T., Matsui, Y. and Shirasaki, N. (2016) Use of orbitrap-MS/MS and QSAR analyses to estimate mutagenic transformation products of iopamidol generated during ozonation and chlorination. Chemosphere $148,233-240$.

Mekonen, S., Argaw, R., Simanesew, A., Houbraken, M., Senaeve, D., Ambelu, A. and Spanoghe, P. (2016) Pesticide residues in drinking water and associated risk to consumers in Ethiopia. Chemosphere 162(Supplement C), 252-260.

Miltner, R.J., Baker, D.B., Speth, T.F. and Fronk, C.A. (1989) Treatment of seasonal pesticides in surface waters. Journal AWWA 81, 43-52.

Misra, D., Sreedharan, B., Bhuyan, S. and Sethunathan, N. (1993) Accelerated degradation of fenitrothion in fenitrothion- or 3 methyl-4-nitrophenolacclimatized soil suspensions. Chemosphere 27(8), 1529-1538.

Nakano, Y., Miyazaki, A., Yoshida, T., Ono, K. and Inoue, T. (2004) A study on pesticide runoff from paddy fields to a river in rural region-1: field survey of pesticide runoff in the Kozakura River, Japan. Water Research 38(13), 3017-3022.

Nam, S.-W., Choi, D.-J., Kim, S.-K., Her, N. and Zoh, K.-D. (2014) Adsorption characteristics of selected hydrophilic and hydrophobic micropollutants in water using activated carbon. Journal of Hazardous Materials 270(Supplement C), 144-152.
Reemtsma, T., Alder, L. and Banasiak, U. (2013) Emerging pesticide metabolites in groundwater and surface water as determined by the application of a multimethod for 150 pesticide metabolites. Water Research 47(15), 5535-5545.

Schipper, P.N.M., Vissers, M.J.M. and van der Linden, A.M.A. (2008) Pesticides in groundwater and drinking water wells: overview of the situation in the Netherlands. Water Science and Technology 57(8), 1277-1286.

Sinclair, C.J., Boxall, A.B.A., Parsons, S.A. and Thomas, M.R. (2006) Prioritization of pesticide environmental transformation products in drinking water supplies. Environmental Science \& Technology 40(23), 7283-7289.

Takanashi, H., Kishida, M., Abiru, K., Kondo, T., Kameya, T., Matsushita, T., Nakajima, T. and Ohki, A. (2013) A screening study on the mutagen formation potential of 44 pesticides. Journal of Water Supply: Research and Technology - Aqua 62(1), 14-22.

Takanashi, H., Hama, T., Nakajima, T., Ohki, A., Kondo, T., Kameya, T. and Matsushita, T. (2014) A screening study of mutagen formation potential (MFP) of pesticide transformation products in water environments (PTPWs) to investigate the MFP changes from their parent pesticides through transformations. Journal of Water and Environment Technology 12(1), 25-32.

Takanashi, H., Hama, T., Nakajima, T., Ohki, A., Ueda, T., Matsushita, T., Kondo, T. and Kameya, T. (2016) Quantitative structure-activity relationship of pesticide and their transformation products in water environments to mutagen formation potential. Environmental science 29, 229-237.

Thuy, P.T., Moons, K., van Dijk, J.C., Viet Anh, N. and Van der Bruggen, B. (2008) To what extent are pesticides removed from surface water during coagulation-flocculation? Water and Environment Journal 22(3), 217-223. 
Vartiainen, T. and Liimatainen, A. (1986) High levels of mutagenic activity in chlorinated drinking water in Finland. Mutation Research/Genetic Toxicology 169(1), 29-34.

von Gunten, U. (2003) Ozonation of drinking water:
Part I. Oxidation kinetics and product formation. Water Research 37(7), 1443-1467. 


\section{Supplementary information}

\section{Removals of pesticides and pesticide transformation products during drinking water treatment processes and their impact on mutagen formation potential after chlorination}

Taku Matsushita $^{1, *}$, Ayako Morimoto $^{2}$, Taisuke Kuriyama $^{2}$, Eisuke Matsumoto $^{2}$, Yoshihiko Matsui $^{1}$, Nobutaka Shirasaki ${ }^{1}$, Takashi Kondo ${ }^{2}$, Hirokazu Takanashi ${ }^{3}$, Takashi Kameya ${ }^{4}$

${ }^{1}$ Faculty of Engineering, Hokkaido University, N13W8, Sapporo 060-8628, Japan

${ }^{2}$ Graduate School of Engineering, Hokkaido University, N13W8, Sapporo 060-8628, Japan

${ }^{3}$ Faculty of Science and Engineering, Kagoshima University, 1-21-40 Korimoto, Kagoshima 890-0065, Japan

${ }^{4}$ Faculty of Environment and Information Sciences, Yokohama National University, 79-7 Tokiwadai, Hodogaya, Yokohama 240-8501, Japan ${ }^{*}$ Corresponding author: taku-m@eng.hokudai.ac.jp, +81-11-706-7279

Table S1 Structures of target compounds used in the present study.

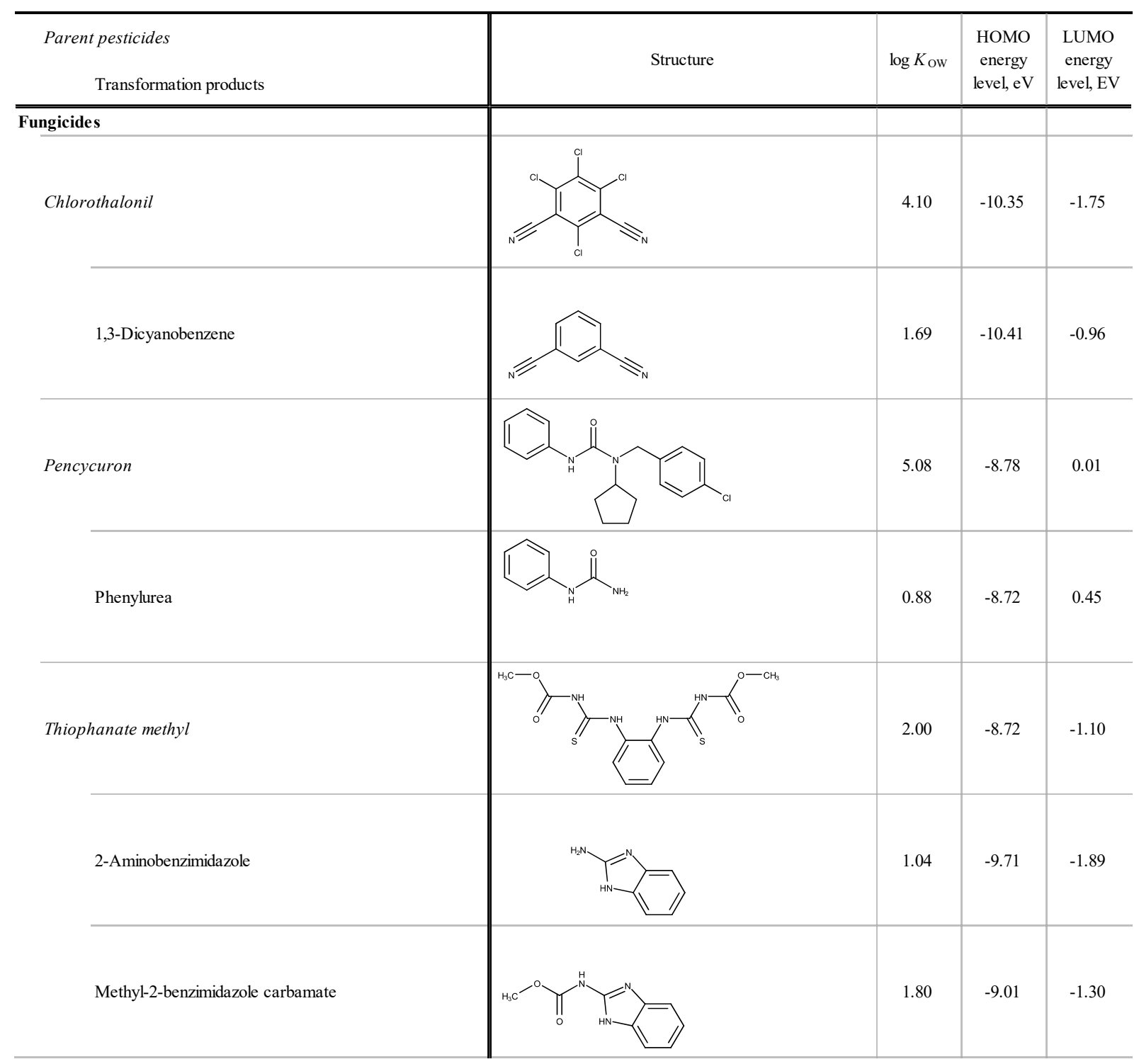


Table S1 (continued)

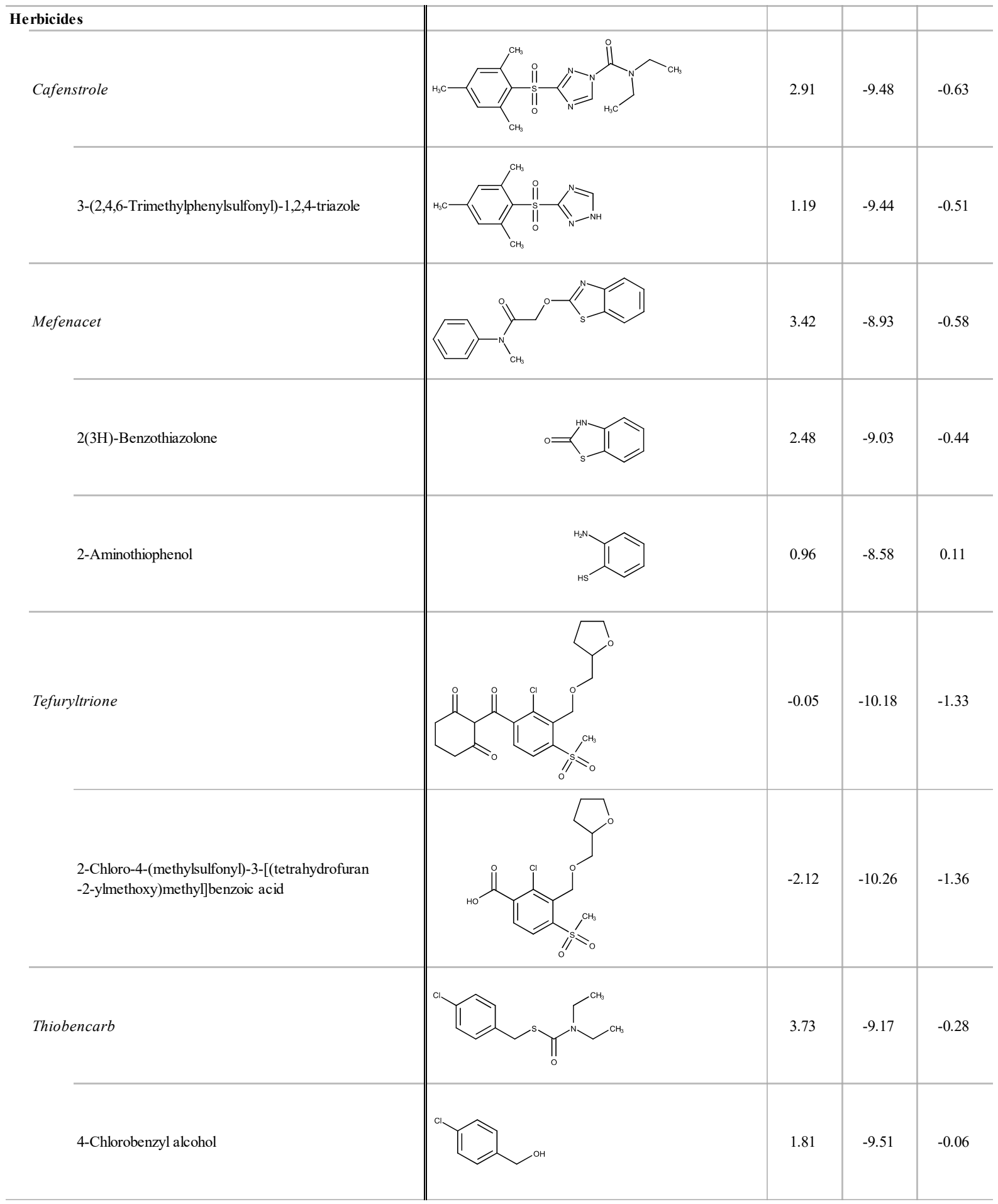


Table S1 (continued)

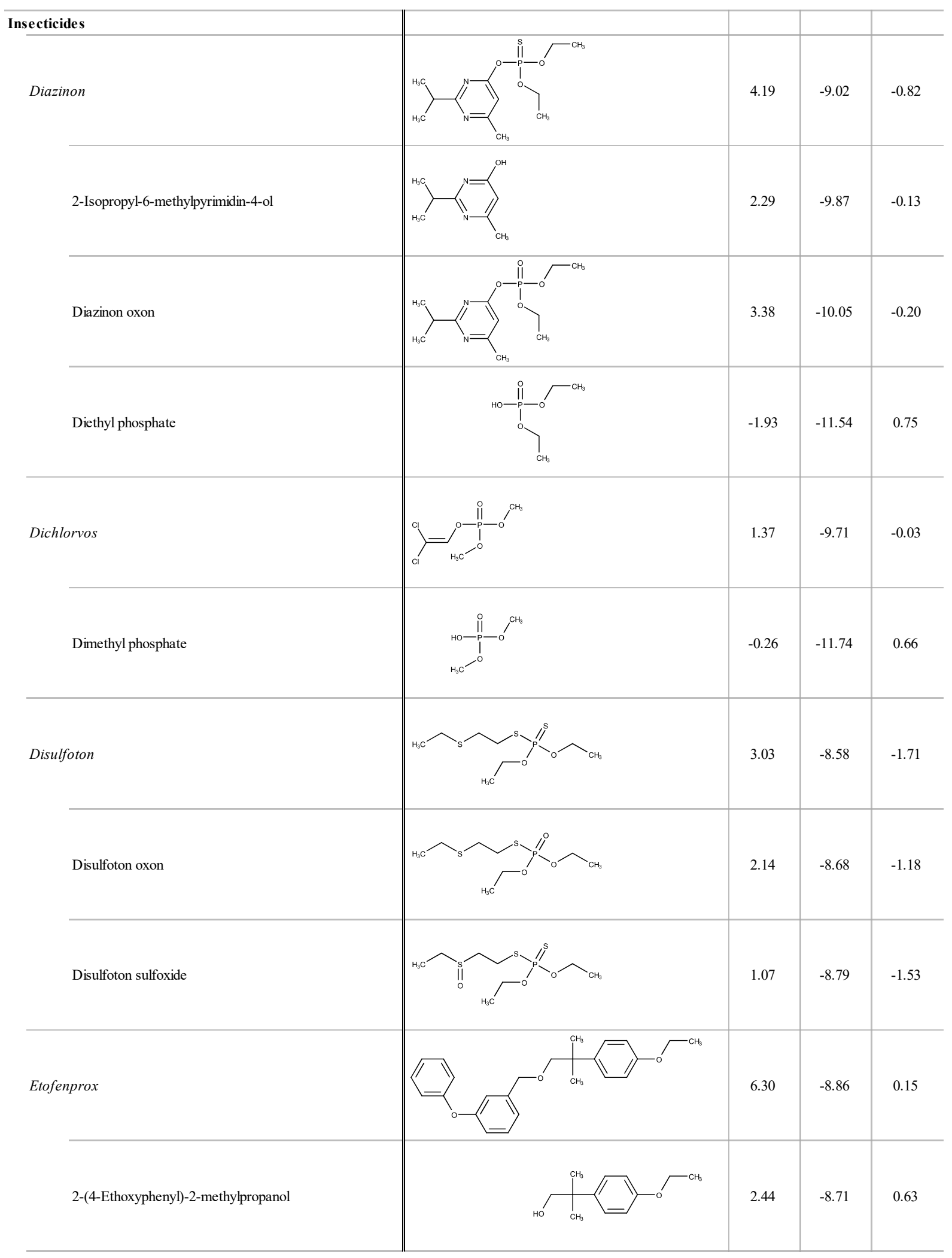


Table S1 (continued)

\begin{tabular}{|c|c|c|c|c|}
\hline Fenitrothion & & 3.12 & -10.36 & -2.02 \\
\hline 3-Methyl-4-nitroanisole & & 2.27 & -9.85 & -0.93 \\
\hline 3-Methyl-4-nitrophenol & & 1.92 & -9.99 & -1.01 \\
\hline Fenitrooxon & & 2.23 & -10.25 & -1.23 \\
\hline Methyl paraoxon & & 1.71 & -10.41 & -1.29 \\
\hline Trimethyl phosphate & & 0.11 & -11.82 & 0.44 \\
\hline
\end{tabular}


Table S1 (continued)

\begin{tabular}{|c|c|c|c|c|}
\hline Malathion & & 1.86 & -10.13 & -2.83 \\
\hline Diethyl fumarate & & 1.43 & -11.34 & -0.92 \\
\hline Diethyl maleate & & 1.43 & -11.23 & -0.52 \\
\hline Diethyl L-(-)-malate & & -0.11 & -11.12 & 0.74 \\
\hline Diethyl L-(+)-tartrate & & -0.82 & -11.05 & 0.50 \\
\hline Malaoxon & & 0.97 & -10.10 & -1.32 \\
\hline Methidathion & & 2.29 & -8.69 & -1.65 \\
\hline Methidathion oxon & & 1.40 & -9.55 & -1.39 \\
\hline Pyriproxyfen & & 4.75 & -8.72 & 0.18 \\
\hline 4-Phenoxyphenol & & 3.17 & -8.80 & 0.13 \\
\hline
\end{tabular}


(a) PAC adsorption

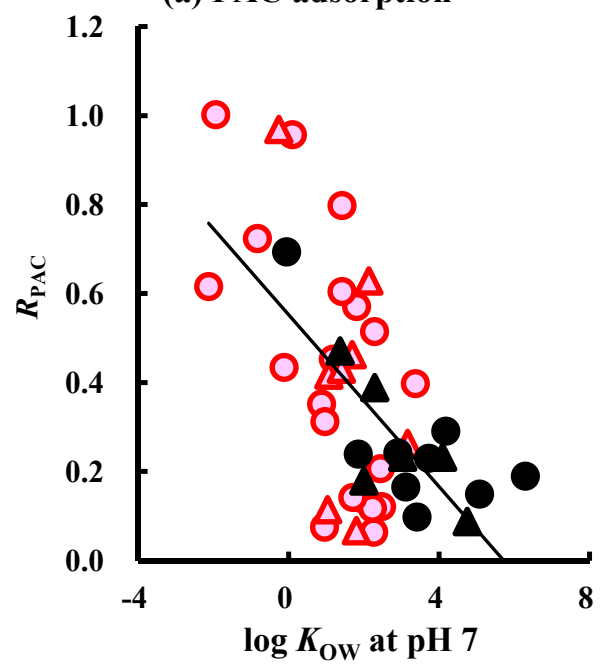

(b) Ozonation

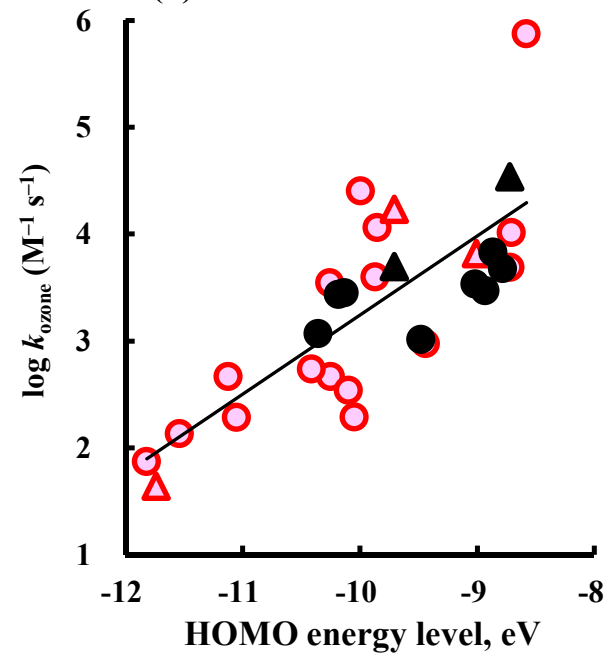

Fig. S1 Comparison between rice-farming and upland-filed pesticides and their TPs. (a) PAC adsorption. (b) ozonation. $\mathrm{O}$, TPs of rice-farming pesticides; $\Delta$, TPs of upland-field pesticides; $\boldsymbol{O}$, rice-farming pesticides; $\boldsymbol{\Delta}$, upland-field pesticides. 